\title{
Saúde mental do idoso no Brasil: a relevância da pesquisa epidemiológica
}

Em dezembro de 2011, o Instituto Brasileiro de Geografia e Estatística (IBGE) divulgou a expectativa de vida da população brasileira no ano de 2010: 73,5 anos. Embora esse índice tenha aumentado em 11 anos nas últimas três décadas, sem dúvida um fato positivo, novos desafios se apresentam. Tomando apenas a saúde mental como foco, o aumento de casos de fragilidade, depressão e demência (gigantes da geriatria e gerontologia) certamente impõe enormes desafios.

No Brasil, uma metanálise estimou em $26 \%$ a proporção de idosos com sintomas clinicamente significativos de depressão (Int Psychogeriatr 2010; 22:712-26). Com relação à demência, estima-se que sejam 24 milhões de indivíduos no mundo, a maioria vivendo em países de baixa renda (Lancet 2005; 366:2112-7). Calcula-se ainda que o crescimento do número de casos de demência, ao longo das próximas décadas, será maior nos países de baixa e média rendas, entre os quais o Brasil se inclui.

Esses dados levantam questões não apenas econômicas e de gestão, mas também para o fomento de pesquisas que possam orientar a adoção de medidas para lidar com esse cenário. Os estudos nacionais de prevalência, incidência e fatores associados à depressão e demência em idosos ainda são fruto de iniciativas de grupos de pesquisas, sobretudo das regiões Sudeste e Sul do país. O mesmo se aplica aos aspectos da funcionalidade e qualidade de vida desse grupo etário.

Porém, junto com esse esforço de ampliação do conhecimento ainda restrito a algumas regiões, é preciso expandir o escopo dos nossos estudos epidemiológicos, enfatizando as alterações do processo de envelhecimento. No caso da depressão, é importante que se enfoque, por exemplo, os limites entre depressão e sintomas depressivos possivelmente adaptativos (U Gerontol 2003; 58:249-65). Já para as demências, são necessários estudos empíricos sobre o processo normal de envelhecimento e sobre as alterações da cognição em seus diversos domínios. É vital que as pesquisas também se concentrem nos determinantes do envelhecimento saudável e no conceito de reserva cognitiva/reserva cerebral.

Essas questões vêm ganhando relevância na agenda de pesquisa da saúde mental da população idosa em países com elevada expectativa de vida. Um exemplo é o Kungsholmen Project, um estudo de coortes com indivíduos acima de 74 anos iniciado na Suécia no final da década de 1980. Entre seus vários tópicos, esse estudo incluiu o funcionamento cognitivo no envelhecimento, o comprometimento cognitivo leve, as fases pré-clínicas da demência e os fatores de risco para demência e doença de Alzheimer.

No entanto, o interesse dos pesquisadores em saúde mental do idoso por esses temas não é suficiente para avançarmos nessa direção. A investigação das questões anteriormente referidas exige estudos populacionais longos e caros, cujos resultados não estarão disponíveis a curto prazo. Desse modo, o papel das agências de fomento em pesquisa será essencial para a produção de conhecimento dos determinantes do envelhecimento saudável.

Evandro Silva Freire Coutinho

Escola Nacional de Saúde Pública Sergio Arouca, Fundação Oswaldo Cruz, Rio de Janeiro, Brasil.

esfcoutinho@ensp.fiocruz.br

Jerson Laks

Instituto de Psiquiatria, Universidade Federal do Rio de Janeiro, Rio de Janeiro, Brasil.

Centro de Estudos e Pesquisa do Envelhecimento, Instituto Vital Brazil, Niterói, Brasil.

jlaks@centroin.com.br 